\title{
Physical capacity and physical strain in persons with tetraplegia; The role of sport activity
}

\author{
AJ Dallmeijer ${ }^{1}$, MTE Hopman ${ }^{2}$, HHJ van $\mathrm{As}^{3}$ and LHV van der Woude ${ }^{1}$ \\ ${ }^{1}$ Institute for Fundamental and Clinical Human Movement Sciences, Vrije Universiteit Amsterdam, The Netherlands; \\ ${ }^{2}$ Institute for Fundamental and Clinical Human Movement Sciences, University of Nijmegen, The Netherlands; \\ ${ }^{3}$ Rehabilitation Centre Amsterdam, The Netherlands
}

To determine the relationship between sport activity and physical capacity (PC) and physical strain (PS) during standardized activities of daily living (ADL), 25 subjects with tetraplegia were studied. To quantify PC, maximal power output, peak oxygen uptake and maximal isometric force were determined on a stationary wheelchair ergometer. PS was described as the highest heart rate (expressed as a percentage of the heart rate reserve), observed during standardized ADL tasks. Multiple regression analyses showed that sport activity, lesion level and completeness of the lesion were the most important determinants of PC. An inverse relationship was found between PS during the ADL tasks and parameters of PC. Parameters of PC and sport activity were significant determinants of PS. It is concluded that a higher PC is associated with a lower PS in daily life, and that sport activity is an important determinant of PC. Although no causal relationships could be established, due to the cross-sectional character of this study, the results support the assumption that being physically active is highly important for individuals with tetraplegia.

Keywords: tetraplegia; activities of daily living (ADL); physical capacity; physical strain; sport activity

\section{Introduction}

It is well established that wheelchair bound individuals with a spinal cord injury (SCI) have a reduced physical capacity (PC), depending on several factors such as the lesion level, age and sex. ${ }^{1}$ In particular, individuals with a cervical SCI, resulting in tetraplegia (TP), have an extremely low PC. ${ }^{2-4}$ Extensive muscle paralysis, resulting in reduction of the function of arms, trunk and legs, the impaired sympathetic cardiac regulation and reduced venous return are the main factors limiting exercise capacity in TP. ${ }^{5-7}$

In prevous studies, it has been shown that a low PC is associated with high peak levels of physical strain (PS) in daily life. ${ }^{8}$ High peak levels of physical strain were observed during activities of daily living (ADL) such as ascending a ramp, changing sheets and making transfers. ${ }^{9,10}$ However, the overall level of PS was considered too low to improve or even maintain cardiovascular fitness. ${ }^{9,10}$ Janssen et $a l^{8}$ measured PS also during standardized ADL in a laboratory situation, and found an inverse correlation between PC and PS for all tasks. This indicates that subjects with a lower PC encounter higher levels of PS in daily life. Consequently, significantly higher levels of PS were observed for TP, compared to subjects with paraplegia. ${ }^{8}$

Correspondence: AJ Dallmeijer, M.Sc., Institute for Fundamental and Clinical Human Movement Sciences, Vrije Universiteit Amsterdam, Van der Boechorststraat 9, 1081 BT Amsterdam, The Netherlands
The high PS during ADL in SCI is suggested to restrict activity in daily life, ${ }^{1}$ primarily as a consequence of increased fatigue and discomfort. A reduced level of physical activity can result, which may in turn lead to a further deterioration of PC. Moreover, a high PS in ADL increases the risk for overloading situations in daily life and thus the risk for musculoskeletal injuries ${ }^{11}$ and cardiovascular diseases. ${ }^{12-14}$ To avoid the risk to develop a sedentary lifestyle, and to reduce the risk for injuries and diseases, it seems to be of the greatest importance to increase PC. An active lifestyle and sports activity appear to be relevant factors in the development of physical fitness, and, consequently, to independence and overall functioning. ${ }^{15,16}$ Previous studies showed that physical activity can improve endurance capacity and muscular strength in individuals with paraplegia and TP. ${ }^{17-20}$ Higher fitness levels were also found cross-sectionally in subjects with SCI who were regularly involved in sports activities, compared to inactive subjects with $\mathrm{SCI}^{3}$ Based on the inverse relationship between PC and $\mathrm{PS},{ }^{8}$ it can be expected that improvements in PC due for example to sport activities will also lead to a reduction of PS in daily life.

Until present, PS during ADL in TP was only investigated by Janssen et $a l^{8}$ in a mixed group of subjects with SCI, including only 9 TP. The present cross-sectional study was performed in order to gain 
insight in the effect of sport activity on PC and PS, among a larger population of TP. The objectives of the work reported here are therefore (1) to quantify PC and PS during standardized ADL; (2) to establish the role of sport activity and other personal characteristics on PC and PS; and (3) to examine the relationship between parameters for PC and PS.

\section{Method}

Subjects and experimental procedure

Twenty-five individuals with TP, (C4-5 to C8), participated after giving their written informed consent. To facilitate comparison with the results of previous studies, subjects were grouped according to lesion level in a high lesion level group (HL; C6 and higher), with 12 subjects (one female), a low lesion level group (LL; lower than C6), of seven male subjects, and a group of six subjects (two female) with incomplete lesions [IL; ASIA Impairment Scale: B $(n=1), \mathrm{C}(n=1)$ and $\mathrm{D}(n=4)]$. The number of subjects per lesion level is shown in Figure 1. Subjects were asked to complete a questionnaire in order to obtain personal data, including sport activity, which was defined as hours sport participation per week. Body weight was measured in sitting position on a hospital scale. Each subject performed a series of ADL tasks, followed by an isometric strength test and a maximal aerobic exercise test. All subjects were asked to consume a light meal only, and to refrain from smoking, drinking coffee and alcohol at least $2 \mathrm{~h}$ prior to testing. To

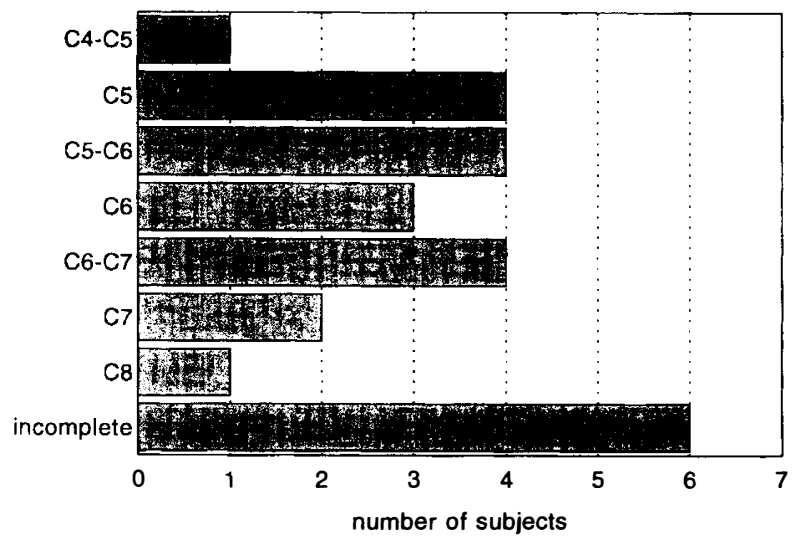

Figure 1 Number of subjects per lesion level avoid autonomic dysreflexia during the tests, subjects were asked to void directly before the test. Subject characteristics (age, body weight, time since injury and sport activity) are listed in Table 1.

\section{Physical capacity}

PC was defined as maximal isometric force $\left(\mathrm{F}_{\text {iso }}\right)$, maximal power output $\left(\mathrm{PO}_{\max }\right)$ and peak oxygen uptake $\left(\mathrm{VO}_{2 \text { peak }}\right)$. Measurements were performed on a computer-controlled, stationary wheelchair ergometer, $^{21}$ which allowed for direct measurements of torques applied on the rim, as well as resultant velocity of the wheels, for the left and right side separately. The wheel and hand rim radii were 0.31 and $0.26 \mathrm{~m}$, respectively. Ergometer settings were individually adjusted. Seat height was standardized at $110^{\circ}$ elbow angle $\left(180^{\circ}\right.$ defined as full extension) with the subject's hands on the top of the rim, and the shoulders (acromion) directly above the wheel axle. ${ }^{22}$ Rear wheel camber was set at $4^{\circ}$. Seat and back-rest angle were set at $5^{\circ}$ (to horizontal) and $15^{\circ}$ (to vertical), respectively.

\section{Isometric strength test}

To measure $\mathrm{F}_{\text {iso }}$, maximal force was exerted to the hand rims during $5 \mathrm{~s}$ with both arms at top dead centre of the blocked rims of the ergometer. Three trials were performed, with a 2 min rest period in between trials. Torque was sampled with a frequency of $50 \mathrm{~Hz}$. Effective isometric force $(\mathrm{F})$ was calculated according to:

$$
\mathrm{F}=\mathrm{M} \cdot \mathrm{r}_{\mathrm{r}}^{-1}
$$

where $\mathbf{M}$ is the rim torque and $r_{r}$ is the rim radius.

$F_{\text {iso }}$ was defined as the highest mean $F$ (averaged over left and right arms) over $3 \mathrm{~s}$. The highest value of the three trials was used for further analyses.

\section{Maximal aerobic exercise test}

$\mathrm{PO}_{\text {max }}, \mathrm{VO}_{2 \text { peak }}$ and respiratory exchange ratio (RER) were determined during a maximal exercise test, consisting of $1 \mathrm{~min}$ exercise bouts at a constant velocity of $0.83 \mathrm{~ms}^{-1}$. Resistance level was estimated from $F_{\text {iso }}$ using a regression equation established by Janssen et al $\left(1993, \mathrm{PO}_{\max }=0.34 \mathrm{~F}_{\text {iso }}-0.02\right) .{ }^{4}$ Starting with an exercise level of $10 \%$ of the estimated $\mathrm{PO}_{\max }$, resistance was increased each bout in equal steps of $10 \%$ of the estimated $\mathrm{PO}_{\max }$. Subjects who were not

Table 1 Subject characteristics for each lesion group

\begin{tabular}{lccccc}
\hline & $\begin{array}{c}\text { High level lesion } \\
(\mathrm{n}=12)\end{array}$ & $\begin{array}{c}\text { Low level lesion } \\
(\mathrm{n}=7)\end{array}$ & \multicolumn{2}{c}{$\begin{array}{c}\text { Incomplete lesion } \\
(\mathrm{n}=6)\end{array}$} & $p$-value \\
\hline Age (years) & $28.7(8.4)$ & $39.1 \quad(11.7)$ & $33.5(11.2)$ & 0.113 \\
Body weight (kg) & $75.6(21.9)$ & $79.1 \quad(13.9)$ & $63.8(13.1)$ & 0.304 \\
Time since injury (years) & $5.3(3.1)$ & $10.1 \quad(11.4)$ & $3.1 \quad(0.9)$ & 0.143 \\
Sport activity (hrs.week $\left.{ }^{-1}\right)$ & $0.7(1.8)$ & $1.4 \quad(1.6)$ & $2.3 \quad(2.3)$ & 0.218 \\
\hline
\end{tabular}


able to maintain the velocity, performed the test at a constant velocity of $0.56 \mathrm{~ms}^{-1}$. Visual feedback of the velocity was provided, and subjects were instructed to maintain velocity at a constant level. The test was terminated when the subject could no longer maintain the imposed velocity due to exhaustion. Verbal encouragement was provided during the test. Torque and linear velocity of the wheels (v) were measured during each exercise bout for $10 \mathrm{~s}$, with a sample frequency of $50 \mathrm{~Hz}$.

Power output (PO) was calculated according to:

$$
\mathrm{PO}=\mathrm{M} \cdot \mathrm{v} \cdot \mathrm{r}_{\mathrm{w}}{ }^{-1}
$$

(Watt)

where $r_{w}$ is the wheel radius.

For each $1 \mathrm{~min}$ exercise bout mean PO (sum of left and right arm) was calculated over $10 \mathrm{~s}$ (complete cycles only). The highest mean PO that occurred during the test was defined as $\mathrm{PO}_{\max }$.

Oxygen uptake and RER were measured continuously during the test with an Oxycon Ox4 (Mijnhardt, The Netherlands). Calibration was performed prior to each test with reference gases. Averaged values over $30 \mathrm{~s}$ were sampled. $\mathrm{VO}_{2 \text { peak }}$ was defined as the highest value recorded during the test, averaged over $60 \mathrm{~s}$.

To measure the maximal heart rate $\left(H R_{\text {peak }}\right)$, heart rate was monitored during the test with a Polar Sport Tester (Polar Electro Incorporation, Finland), set to sampling with a $5 \mathrm{~s}$ interval period. $\mathrm{HR}_{\text {peak }}$ was defined as the highest heart rate found during the test.

\section{Physical strain during $A D L$}

To estimate PS during ADL, the following (shortlasting) standardized tasks were performed: ascending a ramp with an inclination of $3.5^{\circ}$ and a length of $6 \mathrm{~m}$, opening and closing a sliding door and washing hands. During these tasks heart rate was monitored with a Polar Sport Tester that sampled with a $5 \mathrm{~s}$ interval period. To estimate PS, heart rate was expressed as percentage of the individual heart rate reserve (HRR) according to:

$$
\% \mathrm{HRR}=\left[\left(\mathrm{HR}_{\text {act }}-\mathrm{HR}_{\text {rest }}\right) /\left(\mathrm{HR}_{\text {peak }}-\mathrm{HR}_{\text {rest }}\right)\right]^{*} 100
$$

where $\mathrm{HR}_{\mathrm{act}}$ is the actually measured heart rate value and $H_{R}$ rest is the lowest heart rate found during the whole testing period. PS of a task was defined as the highest heart rate provoked by the task, expressed as percentage of the HRR. ${ }^{23}$ To investigate PS during wheelchair propulsion, each subject performed an additional test on the wheelchair ergometer (the same configuration as is described above), in which wheelchair propulsion against a slope of $0.5^{\circ}$ was simulated. Test duration was $3 \mathrm{~min}$ with a constant velocity of $0.83 \mathrm{~ms}^{-1}$. Subjects who were not able to maintain this velocity, performed the test at a constant velocity of $0.56 \mathrm{~ms}^{-1}$. Rolling-resistance coefficient was set at 0.01 . The individual weight of the subject, plus a virtual weight of a wheelchair of $20 \mathrm{~kg}$ was simulated.

\section{Statistics}

One way Analysis of Variance (ANOVA, Tukey posthoc test) was applied to detect differences between the HL, LL and IL group. Pearson correlations were calculated over the total group to establish relationships between parameters of PC and PS, and between parameters of PC, PS, and sport activity. Spearman correlation coefficients were calculated to investigate the relationships between lesion level ( $\mathrm{C} 4$ was ranked as $1, \mathrm{C} 4-\mathrm{C} 5$ as $1.5, \mathrm{C} 5$ as 2 , and so on) and parameters of PC and PS. To establish the most important determinants of parameters of PC and PS, multiple regression analysis was applied, using sport activity, lesion level, time since injury, completeness of the lesion (complete $=1$, incomplete $=0$ ), age, and parameters of PC (for PS only) as independent variables. Level of significance was set at $P<0.05$.

\section{Results}

\section{Subjects}

Results of subject characteristics are summarized in Table 1. No significant differences between the HL, LL and IL group were found for age, body weight, time since injury and sport activity. Sport activity ranged from 0 to $6 \mathrm{~h}$ per week. Of all subjects, 10 participated in quad rugby training for $2 \mathrm{~h}$ per week (HL: $n=2$, LL: $n=4$, IL: $n=4)$. Additional sport activities of these subjects were wheeling $(n=4)$, wheelchair dancing $(n=1)$, wheelchair basketball $(n=1)$, table tennis $(n=1)$, and swimming $(n=1)$.

\section{Physical capacity}

Results for $\mathrm{F}_{\text {iso }}, \mathrm{PO}_{\max }$ and $\mathrm{VO}_{2 \text { peak }}$, relative to body weight, are shown in Figure 2. Significantly lower values for $\mathrm{F}_{\text {iso }}, \mathrm{PO}_{\max }$ and $\mathrm{VO}_{2 \text { peak }}$ were found in the HL group $\left(0.92\right.$ N.kg ${ }^{-1}, 0.16$ Watt.kg ${ }^{-1}$ and 7.7 ml.min. $\mathrm{kg}^{-1}$, respectively), compared to $\mathrm{LL}$ (2.27 N.kg ${ }^{-P}, 0.33$ Watt. $\mathrm{kg}^{-1}$ and $11.4 \mathrm{ml} . \mathrm{min} . \mathrm{kg}^{-1}$ ) and IL $\quad\left(1.90 \mathrm{~N} . \mathrm{kg}^{-1}, \quad 0.39 \quad \mathrm{Watt}^{-1} \mathrm{~kg}^{-1}\right.$ and 14.9 ml.min. $\mathrm{kg}^{-1}$ ). Mean peak RER was 1.11 (sd: 0.13 ), 1.04 (sd: 0.13), and 1.06 (sd: 0.10) for the HL, LL and IL group respectively, and showed no significant differences between lesion groups. After excluding subjects with incomplete lesions, Spearman correlation coefficients of $0.77 \quad(P<0.001), \quad 0.77$ $(P<0.001)$ and $0.65(P<0.01)$ were found for lesion level with $\mathrm{F}_{\text {iso }}, \mathrm{PO}_{\max }$ and $\mathrm{VO}_{2 \text { peak }}$ (all relative to body weight), respectively $(n=19)$. Sport activity was found to correlate significantly with $\mathrm{PO}_{\max } \quad(r=0.67$; $P<0.001)$ and $\mathrm{VO}_{2 \text { peak }}(r=0.73 ; P<0.001)$ for the total group, whereas no significant correlation was found with $F_{\text {iso. }}$

Regression equations, establishing determinants of $\mathrm{F}_{\text {iso, }} \mathrm{PO}_{\max }$ and $\mathrm{VO}_{\text {2peak }}$, are listed in Table 2 . Multiple regression analysis showed that $70 \%$ of the variance $\left(\mathrm{r}^{2}\right)$ of $\mathrm{PO}_{\max }$ can be explained by lesion level, sport activity and completeness of the lesion. Of the 

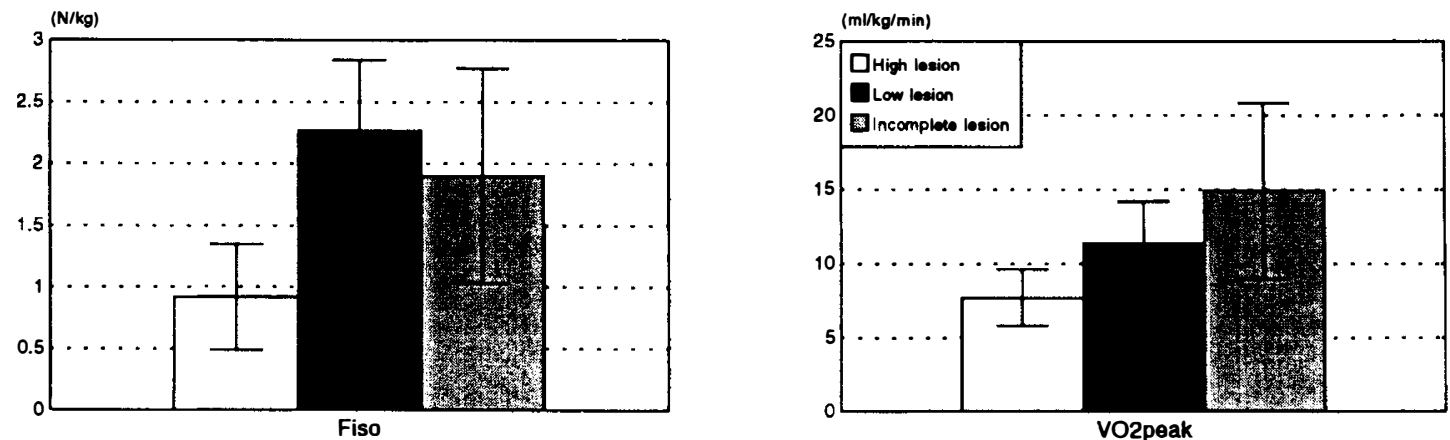

maximal power output

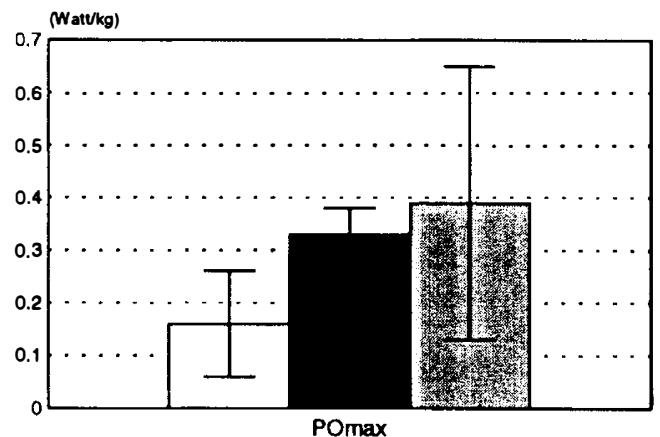

Figure 2 Physical capacity relative to body weight for subjects with a high level lesion (C6 and higher, $n=12$ ), subjects with a low level lesion (lower than C6, $n=7$ ) and subjects with an incomplete lesion $(n=6)$

Table 2 Results of multiple regression analyses to determine parameters for physical capacity [maximal isometric strength $\left(\mathrm{F}_{\text {iso }}\right)$, maximal power output $\left(\mathrm{PO}_{\max }\right)$ and peak oxygen uptake $\left.\left(\mathrm{VO}_{2 \text { peak }}\right)\right]$, using lesion level, sport activity, age, time since injury and completeness of lesion as independent variables

\begin{tabular}{|c|c|c|c|c|}
\hline Dependent variables & $\begin{array}{l}\text { Regression coefficients } \\
+ \text { intercepts }\end{array}$ & Independent variables & p-value & $r^{2}$ \\
\hline \multirow[t]{3}{*}{$\mathrm{F}_{\text {iso }}\left(\mathrm{N} \cdot \mathrm{kg}^{-1}\right)$} & 0.58 & lesion level & 0.008 & 0.21 \\
\hline & -0.98 & completeness of lesion & 0.001 & 0.43 \\
\hline & 0.68 & & 0.120 & \\
\hline \multirow[t]{4}{*}{$\mathrm{PO}_{\max }\left(\mathrm{Watt} . \mathrm{kg}^{-1}\right)$} & 0.052 & sport activity & 0.000 & 0.45 \\
\hline & 0.087 & lesion level & 0.002 & 0.55 \\
\hline & -0.172 & completeness of lesion & 0.004 & 0.70 \\
\hline & 0.093 & & 0.189 & \\
\hline \multirow[t]{3}{*}{$\mathrm{VO}_{2 \text { peak }}\left(\mathrm{ml} \cdot \mathrm{min} \cdot \mathrm{kg}^{-1}\right)$} & 1.43 & sport activity & 0.000 & 0.54 \\
\hline & -3.82 & completeness of lesion & 0.009 & 0.66 \\
\hline & 11.6 & & 0.000 & \\
\hline
\end{tabular}

Table 3 Heart rate at rest $\left(\mathrm{HR}_{\text {rest }}\right)$, peak heart rate $\left(\mathrm{HR}_{\text {peak }}\right)$ and heart rate reserve $(\mathrm{HRR})$ for each lesion group

\begin{tabular}{|c|c|c|c|c|}
\hline & $\begin{array}{c}\text { High level lesion } \\
(\mathrm{n}=12)\end{array}$ & $\begin{array}{c}\text { Low level lesion } \\
(\mathrm{n}=7)\end{array}$ & $\begin{array}{c}\text { Incomplete lesion } \\
(\mathrm{n}=6)\end{array}$ & p-value \\
\hline $\begin{array}{l}\operatorname{HR}_{\text {rest }}\left(\text { b. } \min ^{-1}\right) \\
\operatorname{HR}_{\text {peak }}(\text { b.min } \\
\operatorname{HRR}^{-1} \text { (b.min } \\
\text { HR })\end{array}$ & $\begin{aligned} 54.9 & (8.0) \\
121.1 & (15.7) \\
65.5 & (12.7)\end{aligned}$ & $\begin{aligned} 56.6 & (6.5) \\
125.7 & (11.3) \\
66.9 & (10.0)\end{aligned}$ & $\begin{array}{rr}59.2 & (10.1) \\
150.8 & (25.6) \\
85.3 & (23.3)\end{array}$ & $\begin{array}{l}0.587 \\
0.008 \dagger \S \\
0.008 \dagger\end{array}$ \\
\hline
\end{tabular}

$\dagger$ significant differences between the high level lesion group and the incomplete lesion group. $\S$ significant differences between the low level lesion group and the incomplete lesion group 


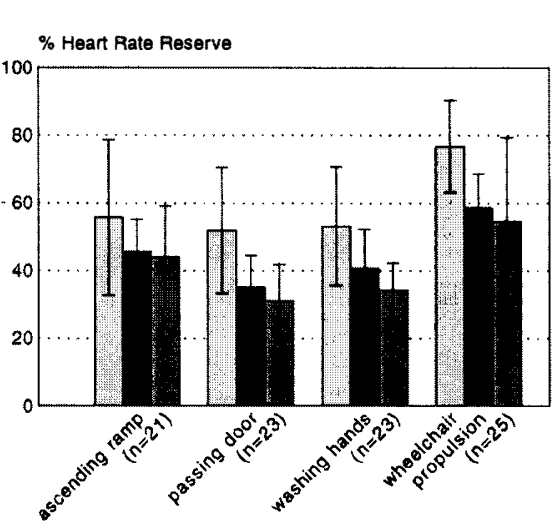

$\square$ High lesion

Low lesion

Incomplete lesion

Figure 3 Physical strain during standardized ADL, expressed as percentage of the heart rate reserve (\%HHR) for subjects with a high lesion level (C6 and higher, $n=12$ ), subjects with a low lesion level (lower than C6, $n=7$ ) and subjects with an incomplete lesion $(n=6)$

variance in $\mathrm{VO}_{2 \text { peak }}, 66 \%$ can be explained by sport activity and completeness of the lesion. Only $43 \%$ of the variance of $F_{\text {iso }}$ was accounted for by lesion level and completeness of the lesion. Age and time since injury were no significant determinants of PC.
Physical strain during $A D L$

Mean $\mathrm{HR}_{\text {rest }}$ showed no significant differences between groups, while mean $\mathrm{HR}_{\text {peak }}$ was significantly lower for subjects with complete lesions $\left(121 \mathrm{~b} \cdot \mathrm{min}^{-1}\right.$ for HL and 126 b. $\min ^{-1}$ for LL), compared to IL (151 b $\min ^{-1}, P<0.01$, see Table 3). Figure 3 displays the mean PS during ascending a ramp, passing a door, washing hands, and wheelchair propulsion. In the HL group, four subjects were not able to ascend the ramp and two subjects were not able to pass the door, due to their low level of PC. Another two subjects of the HL group were not able to wash their hands. For the HL group, significantly higher values were found for PS during passing a door (52\% HRR), washing hands (53\% HRR) and wheelchair propulsion (77\% HRR), compared to the other groups.

Significant correlations were determined between lesion level (for complete lesions only; $n=19$ ) and PS during passing a door $(-0.51, P<0.05)$ and wheelchair propulsion $(-0.50, \quad P<0.05)$. Sport activity showed significant negative correlations with PS during passing a door $(r=-0.42 ; P<0.05)$, washing hands $(r=-0.51 ; P<0.05)$ and wheelchair propulsion $(r=-0.51 ; P<0.01)$.

Table 4 shows the correlation coefficients between PS during the standardized ADL tasks and parameters for PC. PS demonstrated a significant negative

Table 4 Correlation coefficients between physical strain during standardized ADL tasks and parameters of physical capacity [maximal isometric strength $\left(\mathrm{F}_{\text {iso }}\right)$, maximal power output $\left(\mathrm{PO}_{\max }\right)$ and peak oxygen uptake $\left(\mathrm{VO}_{2 \text { peak }}\right)$ ]

\begin{tabular}{|c|c|c|c|c|}
\hline & $\begin{array}{c}\text { Ascending a ramp } \\
(\% \text { HRR }) \\
\mathrm{n}=21\end{array}$ & $\begin{array}{c}\text { Passing a door } \\
(\% H R R) \\
\mathrm{n}=23\end{array}$ & $\begin{array}{l}\text { Washing hands } \\
(\% H R R) \\
\mathrm{n}=23\end{array}$ & $\begin{array}{c}\text { Wheelchair propulsion } \\
(\% H R R) \\
\mathrm{n}=25\end{array}$ \\
\hline $\mathrm{F}_{\text {iso }}(\mathrm{N})$ & -0.54 & -0.54 & ns & -0.64 \\
\hline $\mathrm{F}_{\text {iso }}\left(\mathrm{N} . \mathrm{kg}^{-1}\right)$ & -0.47 & -0.58 & -0.41 & -0.69 \\
\hline $\mathrm{PO}_{\max }(\mathrm{Watt})$ & -0.53 & -0.57 & ns & -0.82 \\
\hline $\mathrm{PO}_{\max }$ (Watt.kg ${ }^{-1}$ ) & -0.48 & -0.58 & -0.41 & -0.85 \\
\hline $\mathrm{VO}_{2 \text { peak }}\left(1 . \mathrm{min}^{-1}\right)$ & -0.47 & -0.48 & -0.42 & -0.55 \\
\hline $\mathrm{VO}_{2 \text { peak }}\left(\mathrm{ml} \cdot \mathrm{min} \cdot \mathrm{kg}^{-1}\right)$ & ns & -0.52 & -0.45 & -0.63 \\
\hline
\end{tabular}

ns: not significant

Table 5 Results of multiple regression analyses to determine physical strain, using parameters of physical capacity [maximal isometric strength $\left(\mathrm{F}_{\text {iso }}\right)$, maximal power output $\left(\mathrm{PO}_{\max }\right)$ and peak oxygen uptake $\left(\mathrm{VO}_{2 \text { peak }}\right)$ ], lesion level, sport activity, age, time since injury, completeness of lesion and weight as independent variables

\begin{tabular}{|c|c|c|c|c|}
\hline Dependent variables & $\begin{array}{l}\text { Regression coefficients } \\
+ \text { intercepts }\end{array}$ & $\begin{array}{l}\text { Independent } \\
\text { variables }\end{array}$ & $p$-value & $r^{2}$ \\
\hline$\% \mathrm{HRR}$ ascending ramp & $\begin{array}{l}-0.151 \\
68.4\end{array}$ & $\mathrm{~F}_{\text {iso }}(\mathrm{N})$ & $\begin{array}{l}0.011 \\
0.000\end{array}$ & 0.29 \\
\hline$\%$ HRR passing door & $\begin{array}{l}-0.59 \\
58.2\end{array}$ & $\mathrm{PO}_{\max }\left(\right.$ Watt.kg $\left.{ }^{-1}\right)$ & $\begin{array}{l}0.003 \\
0.000\end{array}$ & 0.34 \\
\hline$\% \mathrm{HRR}$ washing hands & $\begin{array}{l}-4.10 \\
50.2\end{array}$ & sport activity (hrs.week ${ }^{-1}$ ) & $\begin{array}{l}0.013 \\
0.000\end{array}$ & 0.26 \\
\hline$\%$ HRR wheelchair propulsion & $\begin{array}{r}-92.6 \\
91.0\end{array}$ & $\mathrm{PO}_{\max }\left(\mathrm{Watt} . \mathrm{kg}^{-1}\right)$ & $\begin{array}{l}0.000 \\
0.000\end{array}$ & 0.73 \\
\hline
\end{tabular}


relationship with $\mathrm{PC}$ for all ADL tasks, with values ranging from $r=-0.41$ (washing hands and $\mathrm{PO}_{\max }$ ) to $\mathrm{r}=-0.85$ (wheelchair propulsion and $\mathrm{PO}_{\max }$ ). A stronger relationship was observed for simulated wheelchair propulsion than for short-lasting ADL tasks.

Table 5 presents the results from multiple regression analyses, establishing determinants of PS during standardized ADL tasks. Parameters of PC and sport activity were significant determinants of PS during standardized ADL, explaining $26-73 \%$ of the variance of PS.

\section{Discussion}

\section{Physical capacity}

The low values for $\mathrm{F}_{\text {iso }}, \mathrm{PO}_{\max }$ and $\mathrm{VO}_{2 \text { peak }}$ illustrate the low PC of TP (Figure 2). The considerable inter individual differences indicate that, even within the group of persons with TP, a high degree of variation exists in PC. Results for $\mathrm{VO}_{2 \text { peak }}$ and $\mathrm{PO}_{\max }$ are consistent with previous reports on wheelchair exercise testing in TP..$^{3,4,24-26}$ Results for $F_{\text {iso }}$ are in accordance with the values found for TP in a previous study, using the same experimental set up. ${ }^{4}$ The dependency of PC on the level of injury (see Figure 2 and Table 2) was also found in previous investigations. ${ }^{20,26}$

In the present study, increments per exercise bout of the maximal exercise test were lower than 6 Watt (except for one subject with an incomplete lesion), which is in accordance with recommendations by Lasko-McCarthey et $a^{26}$ to obtain optimal maximal exercise performance in TP. However, several (five) subjects did not reach one of the objective criteria for maximal exercise performance (ie, RER $>1.0$ ). This finding indicates that these subjects were not maximally stressing the cardiovascular system. Apparently, other factors, such as local muscular fatigue, may have forced the subjects to terminate the test, which may have resulted in an underestimation of $\mathrm{HR}_{\text {peak }}, \mathrm{PO}_{\text {max }}$ and $\mathrm{VO}_{\text {2peak }}$.

Physical strain during $A D L$

Absolute heart rate does not seem an adequate measure to estimate PS, because heart rate is usually lowered in persons with complete TP, due to the disturbed cardiac innervation. ${ }^{6}$ Heart rate expressed as percentage of the HHR provides a relative measure to estimate $\mathrm{PS},{ }^{23}$ since a correction is made for interindividual differences in $\mathrm{HR}_{\text {peak }}$ and $\mathrm{HR}_{\text {rest }}$. Although all tasks were standardized as far as possible, there probably still remain uncontrolled factors, such as differences in wheelchair configurations and performance speed, which might have influenced the results.

PS during standardized ADL was found to be notably high in TP (Figure 3). This underlines the assumption that TP frequently encounter physically stressful situations in daily life. Although comparison is limited due to the variation in task characteristics and conditions, PS during ADL appeared to be higher than previous results in paraplegics and comparable to the results for TP. ${ }^{8}$ One should notice that the inability to perform certain tasks (ascending a ramp, passing a door), of several subjects with low levels of PC, may have yielded an underestimation of PS in the HL group. Whereas Janssen et $a l^{8}$ found the highest PS during making transfers, in the present study no transfer-tasks were investigated because most subjects with TP are not able to perform transfers independently.

The inverse relationship between PC and PS of short-lasting ADL (Table 4), is in good agreement with previous results of subjects with different lesion levels. ${ }^{8}$ Correlation coefficients for the short-lasting tasks range from -0.41 to -0.58 in the current study, and from -0.40 to -0.66 in the study of Janssen $e t$ $a l^{8}$ In the present study, the correlation between PC and PS during simulated wheelchair propulsion $(r=-0.55$ to -0.85$)$ was stronger than for the short-lasting activities, which may have been due to the fact that test duration ( $3 \mathrm{~min}$ ) was long enough to reach a steady state condition, and that testing conditions were highly standardized.

\section{Sport activity}

Sport activity was the most important determinant for $\mathrm{PO}_{\max }$ and $\mathrm{VO}_{\text {2peak }}$ (Table 2). The considerable percentage of variance of PC explained by sport activity, lesion level and completeness of the lesion $\left(\mathrm{PO}_{\text {max }}: 70 \%, \mathrm{VO}_{2 \text { peak }}: 66 \%\right)$, points towards the positive effect of sport activity on the PC of persons with TP. However, bias due to the cross-sectional character of this study should be taken into account; better performing persons are more likely to participate in sport activities. To establish causal relationships between physical activity and changes in PC and PS, longitudinal research is inevitable.

Multiple regression analyses showed that parameters of PC and sport activity are the most important determinants of PS during ADL tasks irrespective of lesion level, time since injury, completeness of the lesion, body weight and age (Table 5). The inverse relationship between PS during ADL and PC indicates that TP with higher PC levels and those who are more physically active, encounter lower levels of PS in daily life. In order to increase PC, individuals with TP should be strongly encouraged to be physically active, for example to participate in sport activities.

\section{Conclusion}

It is concluded that TP have an extremely low PC and that they encounter high levels of PS during daily life. The inverse relationship between PC and PS during ADL, the positive influence of sport activity on PC, 
and the fact that parameters of PC and sport activity are the most important determinants of PS, support the assumption that being physically active (i.e., participation in sport activity) is highly important in TP.

\section{Acknowledgements}

Support for this project was provided by the Prevention Fund, The Netherlands, The Netherlands Federation for Adapted Sports, The Netherlands, Arjo Mecanaid b.v., Tiel, The Netherlands and the Rehabilitation Centre Amsterdam, The Netherlands. The authors gratefully thank MHM Mertens and MH Kal for their participation in the data collection.

\section{References}

1 Hoffman MD. Cardiorespiratory fitness and training in quadriplegics and paraplegics. Sports Med 1986; 3: 312-330.

2 Loan MD van, McCluer S, Loftin JM, Boileau RA. Comparison of physiological responses to maximal arm exercise among ablebodied, paraplegics and quadriplegics. Paraplegia 1987; 25: 397 405.

3 Eriksson P, Lofstrom L, Ekblom B. Aerobic power during maximal exercise in untrained and well-trained persons with quadriplegia and paraplegia. Scand J Rehab Med 1988; 20: 141 147.

4 Janssen TWJ et al. Isometric strength, sprint power, and aerobic power in individuals with a spinal cord injury. Med Sci Sports Exerc 1993; 25: $863-870$.

5 Hopman MTE, Oeseburg B, Binkhorst RA. Cardiovascular responses in paraplegic subjects during arm exercise. Eur J Appl Physiol 1992; 65: $73-78$.

6 Figoni SF. Exercise responses and quadriplegia. Med Sci Sports Exerc 1993; 25: $433-441$.

7 McLean KP, Jones PP, Skinner JS. Exercise prescription for sitting and supine exercise in subjects with quadriplegia. Med Sci Sports Exerc 1995; 27: 15-21.

8 Janssen TWJ et al. Relationship between physical capacity and physical strain during standardized ADL tasks in men with spinal cord injuries. Paraplegia 1994; 32: 844-859.

9 Hjeltes N, Vokac Z. Circulatory strain in everyday life of paraplegics. Scand J Rehab Med 1979; 2: 67-73.

10 Janssen TWJ, Oers CAJM van, Woude LHV van der, Hollander AP. Physical strain in daily life of wheelchair users with spinal cord injuries. Med Sci Sports Exerc 1994; 26: 661-670.
11 Pentland WE, Twomey LT. Upper limb function in persons with long term paraplegia and implications for independence: Part I. Paraplegia 1994; 32: $211-218$.

12 Le CT, Price M. Survival from spinal cord injury. J Chron Dis 1982; 35: 487-492.

13 Dearwater SR, et al. Activity in the spinal cord injured patient: an epidemiologic analysis of metabolic parameters. Med Sci Sports Exerc 1986; 18: $541-544$.

14 Yekutiel M, et al. The prevalence of hypertension, ischaemic heart diseases and diabetes in traumatic spinal cord injured patients and amputees. Paraplegia 1989; 27: 58-62.

15 Noreau L, Shephard RJ. Physical fitness and productive activity of paraplegics. Sports Med Training and Rehab 1992; 3: 165-181.

16 Hart KA, Rintala HR. Long-term outcomes following spinal cord injury. NeuroRehabil 1995; 5: 57-73.

17 Gass GC, et al. The effects of physical training on high-leve spinal lesion patients. Scand J Rehab Med 1980; 12: 61-65.

18 Cooney MM, Walker JB. Hydraulic resistance exercise benefits cardiovascular fitness of spinal-cord injured. Med Sci Sports Exerc 1986; 18: $522-525$.

19 DiCarlo SE. Effect of arm ergometry training on wheelchair propulsion endurance of individuals with quadriplegia. Phys Ther 1988; 68: 40-44.

20 McLean KP, Skinner JS. Effect of body training position on outcomes of an aerobic training study on individuals with quadriplegia. Arch Phys Med Rehabil 1995; 76: 139-150.

21 Niesing RF, et al. A computer controlled wheelchair ergometer. Med \& Biol Engin \& Comput 1990; 28: 329-338.

22 Woude LHV van der, Veeger HEJ, Rozendal RH, Sargeant AJ. Seat height in hand rim wheelchair propulsion. J Rehabil Res Dev 1989; 26: $31-50$.

23 Janssen TWJ, Oers CAJM van, Woude LHV van der, Hollander AP. Reliability of heart rate response to non-steady-state activities of daily living in men with spinal cord injuries. Scand J Rehab Med 1994; 26: 71-78.

24 Coutts KD, Rhodes EC, McKenzie DC. Maximal exercise responses of tetraplegics and paraplegics. J Appl Physiol: Respirat Environ Exercise Physiol 1983; 55: 479-482.

25 Burkett LN, Chisum J, Stone W, Fernhall B. Exercise capacity of untrained spinal cord injured individuals and the relationship of peak oxygen uptake to level of injury. Paraplegia 1990; 28: 512521.

26 Lasko-McCarthy P, Davis JA. Effect of work rate increment on peak oxygen uptake during wheelchair ergometry in men with quadriplegia. Eur J Appl Physiol 1991; 63: 349-353. 